\title{
Study and Comparison of Inlet Air Cooling Technique of Gas Turbines and Their Effects on Increase of the Efficiency and Outlet Power
}

\author{
Seyed Ali Sakhaei and Mahbod Safari
}

\begin{abstract}
This paper is about to study and compare cooling techniques and utilized systems to cool inlet air of power producing gas turbines. For years, the effect of lessening the temperature of the inlet air in the compressor on both the power and the efficiency has been known very well. Recently, fog pumping method as a substitute for prevalent evaporative coolers has been regarded and the cooling cycles for chilling inlet air in the gas turbines in order to decrease temperature to scale down the outlet power. To evaluate all selection or choices for applying cooling, the most arbitrary, possible method, in respect to the condition of exploitation and environment of site, causes power increase for producers and prevision of potential ability to cost frugality of users. These papers aim to describe and compare inlet cooling systems to gas turbines and especially fog pumping techniques with different environmental conditions in inlet gate. In spite of presenting the economical justification of studying systems not fully, but a relative analogy among given methods will be done.
\end{abstract}

Index Terms - Gas turbine, inlet air, vapourific chilling, fog pumping.

\section{INTRODUCTION}

This paper will discuss the following four cooling methods:

1) Prevalent evaporative cooling systems: In this method, in the entrance of filter chamber, a hive-shaped humid field is installed that cools the inlet air by circulating water and vaporizing it in the field of action. Generally such system is effective to go down the compressor inlet air temperature to the ideal conditions of the environment ( $85 \%$ to $90 \%$ ).

2) Fog pumping systems: The organic water is sprayed directly into inlet air current and water drop vaporization in the inlet air causes cooling it. This sort of system regulates compressor's inlet air temperature to the degree, which is higher partially than wet temperature of the environment.

3) Mechanical chilling: To cool the inlet air by series of fan-tubes in the entrance filter, a chilling system used. Generally such system guaranties for certain dry inlet temperature and based on the maximum conditions of environmental design. These kinds of systems may have a secondary circulating cycle of Glycol-water in the fan-tubes and also the filter chamber.

4) Thermal storage: For thermal storage, the chilling system is applied. However, a great amount of glycol-water

Manuscript received November 29, 2013; revised March 20, 2014.

Seyed Ali Sakhaei is with Faculty of Mechanic in Eyvanekey Institute of Higher Education, Iran (e-mail: Ali0172010@gmail.com).

Mahbod Safari is with Islamic Azad University Tehran East Branch, Iran (e-mail: Mahbodsafari.un@gmail.com). the inlet air circulates into the fan-tubes or pipes in order to decrease the internal power consumption of chilling system during climate load periods.

\section{How to IMPROVE GAS TURBINE PERFORMANCE (TURNOVER)}

Whatever mass Debbie of inlet air flow gas up, paralleling outlet power of gas turbine in the fixed amount of other variable increases as well. To stable the volume Debbie of inlet air flow to gas turbine by growth of the density of the inlet air, the mass Debbie of air flow will be increase as the production power of a relative function comes from the mass Debbie of air flow. If the mass Debbie of additional fuel is ignored, the equation of ideal gas towards mass Debbie flow is as follows [1]:

$$
M=P V / R T
$$

The most common method, which is being utilized to produce the power for increasing mass Debbie, would be air density increase with using the temperature decrease of inlet air. As demonstrated in picture 1 (Fig. 1), as the inlet air temperature becomes smaller in degree (until 20 Fahrenheit degree) correction coefficient of the power increase approximately seven percent [2].

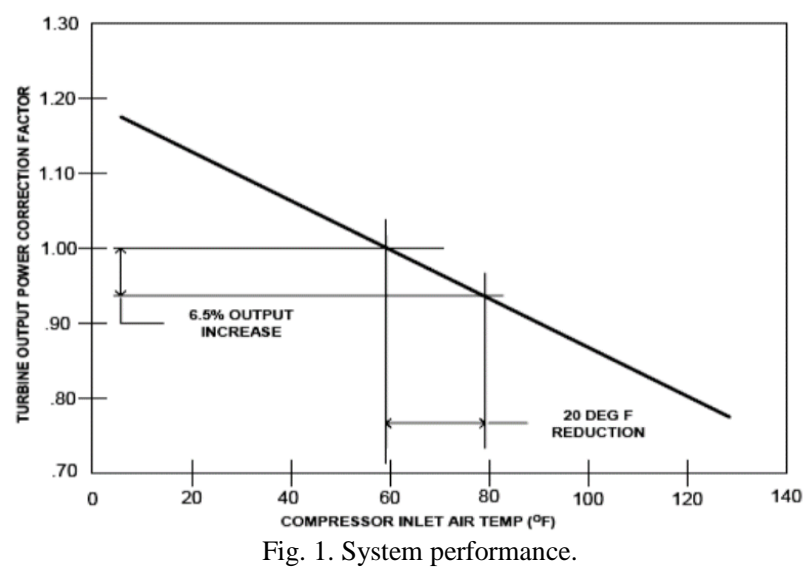

\section{PSYCHROMETRIC PROCESS FOR COOLING INLET AIR}

Evaporating cooling techniques and mechanical chilling cause's inlet air temperature via different psychrometric process. Fig. 2 shows these differences. Intel environment conditions is considered based on wet temperature and 40 degrees of relative humid. In the evaporating cooling system, humid bed method and/or fog pumping process, water can 
absorb the heat via contact with the air flow and a part of fluid water would be evaporate. As while air heat is transferring to the water, air temperature along with a monotonous line of wet temperature goes down (temperature enthalpy, without waste or achievement of heat) and at the same time. Humidity also adds up, this matter has been shown in the process line of 1-2 (a humid environment with 85\% effect) and 1-3 (fog pumping approaching two degrees to the saturation conditions). As you can see in this ex, the expecting inlet temperature for both conditions decreases approx. $18^{\circ} \mathrm{F}$.

The process line of cold fluid of coil chiller indicated in the 1-4-5 process line. As inlet air process over cold coil, the scale of existing water vapor (humidity ratio). Stay steady the 1-4 process line according to temperature decrease until the saturation curve. If the inlet air gets cooler, the process line of the curve function is saturated, 4-5 line indicates the inlet air distillation. The ex. above shows the temperature decrease approx. until $15^{\circ} \mathrm{F}$.

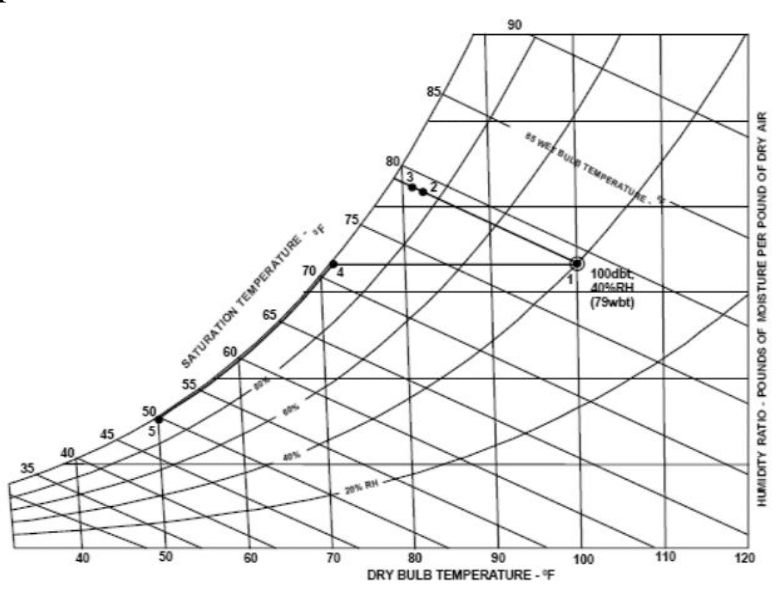

Fig. 2. Evaporative Psychrometric process and coil chilling.

\section{EVAPORATING COOLING SYSTEMS BASED ON HUMID BED}

\section{A. General Features}

In such a system, a waved bed which its basic material cellulose or Fiberglass is used. This an inactive system that is installed in the air path it is humidified via the headers of water distributor. The structure of this environment has, a shape that lets water seep in itself, from one side the water which hasn't been vaporized, goes into the water pool and the other side. Air flow channels are located to transfer the effective heat and minimize the pressure drop enough. As the air flow circulates through the humid bed, the heat transferring starts as well. The existing heats in the air flow is attracted by the environment. So, the vaporized water decrease the inlet air temperature. Psychrometric process path indicated in the graph two which occurred along the permanent Enthalpy line. Effectiveness span of following vaporizing coolers (chillers) as samples ranges from $85 \%$ to $90 \%$ which is defined as below [3];

$$
\text { Effectiveness }=\left(T_{1 D B}-T_{2 D B}\right) /\left(\left(T_{1 D B}-T_{2 W B}\right)\right.
$$

where:

$$
\begin{gathered}
T_{1 D B}=\text { Entering Air Bulb Temperature } \\
T_{2 D B}=\text { Leaving Air Dry Bulb Temperature } \\
T_{2 W B}=\text { Leaving Air Wet Bulb Temperature }
\end{gathered}
$$

Effectiveness is an index (or an indicator) to indicate the scale of vaporizing coolers capability to make close the inlet dry air to humid temperature with its equivalence.

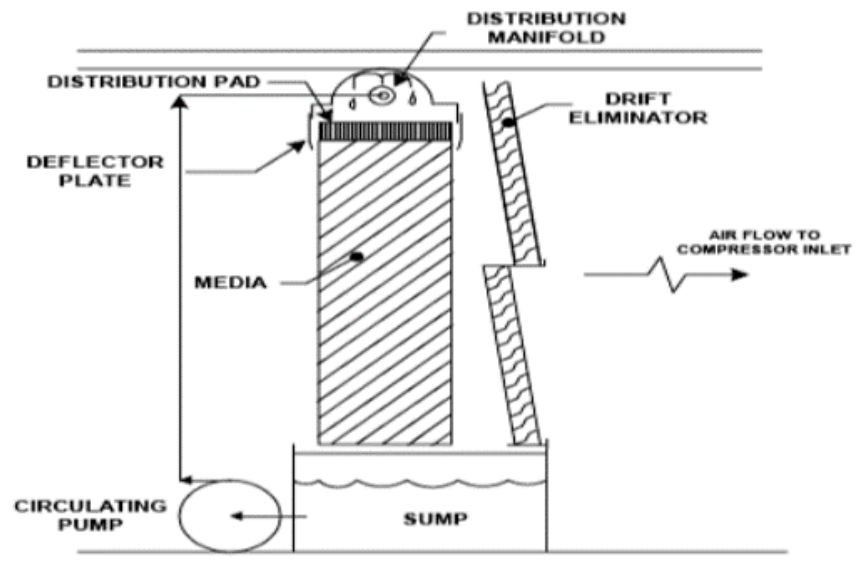

Fig. 3. A section of vaporizing cooler.

Fig. 3 shows a section of a humidity-based vaporizing cooler (chiller). A circulating pumps also transfers the accumulated water in the sewage cavity toward distributive multi-way. Via the way above, water is sprayed on the distributive pad and then is leaked which simultaneously lets the air pass from this field. To protect sub-features of the system from loss rising from extra water, same extra-water eliminators to hold up water drops.

\section{B. Application}

Although evaporating coolers (chillers) operate based on the environment in the wide ranges of climate conditions, but their highest advantage comes out, when they are applied in the hot and dry weather. The certain variables such as water quality, cost, pollution and exploiting from a power planet (continuously or the peak conditions), can limit using vaporizing coolers.

\section{Economic Features}

Generally the bed-based coolers have the lowest cost and of installation and exploitation, in comparison with other introduced systems in this essay. In general, the installation cost from 25-50 dollars in each $\mathrm{KW}$ will be added to the power planet cost. Due to the system simplicity and limited peripheral equipment use, exploitation costs decrease.

\section{The Other Advantages, Risks and Consideration}

When the speed of outlet air on the bed is approximately less than 700 feet per minute (FM), water distribution will be fixed between one and tree gallon in minute for each square feet from distribution pad (depends on environment conditions), that the base of system with the low risk of water spray transferring with the use of the extra water eliminator will be shaped. The humid-based cooling systems are that are flexible with different quality controls of potable water. When the water analysis valuated and Debbie rate of the depletion of water-cooler will be calculated. According to suggested parameters, if Debbie rate is fixed in a favorable amount, then the system will be regulated and the minimum automatic controls will be needed as well. Due to the possible fundamental changes in the inlet water quality, periodical check and water analyzing should be done based on a scheduled suggestive time. Naturally non-mineral water also 
can be used, as regards, in respect to possible reaction of water hardship with the humid bed, there is a possibility that the bed softens in the verge of rupture. If the water is used with its high purity, same discretionary measures must be taken, especially about the material which has been used in piping and consumed features or elements in the under stream.

\section{FOG-PUMPING SYSTEM}

\section{A. General Features}

The high-pressure fog-pumping systems are applied for cooling the inlet air into the gas turbine in order to increase the output power of the turbine. In 1980, this method has been used for the first time [4]. Recently, this technology for bigger industrial gas turbine with the higher output have been used. It should be noticed that the presence of water in the air flow causing erosion and damage which should be restrained or minimized the performance base of such. System will be explaining in the following:

None-mineral water sprays as water drops to distribute the inlet air through a series of distribution multi-ways which consist of multi-shaped nozzles. Some of nozzle manufactures claim that $90 \%$ of water drops have 20 microns or less, however, test techniques basically have changed and comparison of lab test isn't being taken the serious. It is resulted that nozzle's performance for the correct operation of the fog-pumping system is critical. Multi-ways used for prolonging the stay time to the complete vaporization. Debbie injection by comparing the wet temperature of the environment $\left(T_{w b}\right)$ and the dry temperature of inlet air of the compressor (CIT) by measuring tools of the local weather station will be controlled (see Fig. 4).

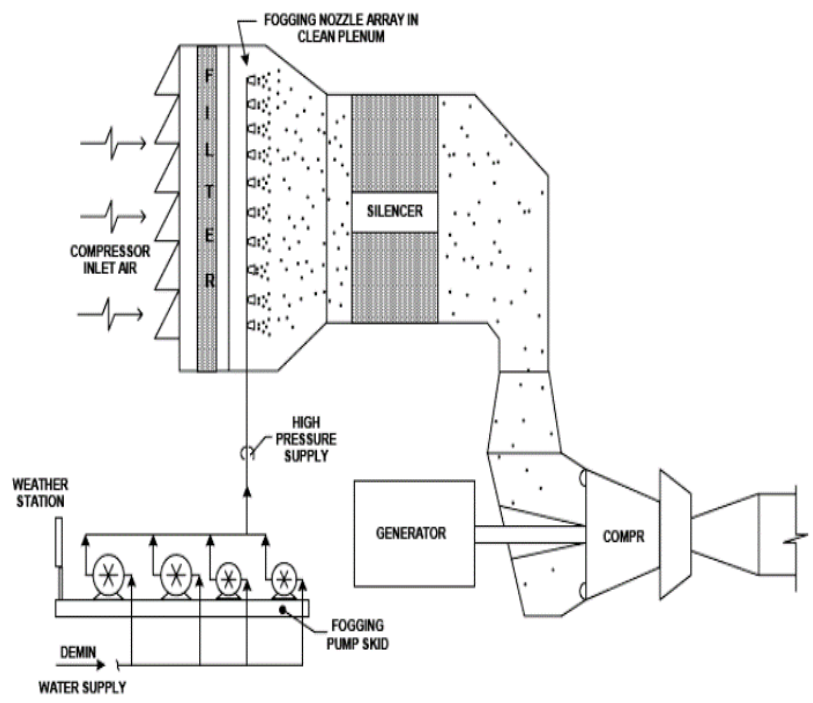

Fig. 4. Cooling system with fog-pumping method.

In this system, to increase flow Debbie to gallons per minute, pumps with various sizes are applied. The control span temperature degree from saturation temperature of $T_{w b}$ with operation band of 1.5 degree is upper the control span, which is possible to down the amount of pump and engine rotation (see Fig. 5).

$$
C I T=T_{w b}+2(+1.5 / 0.0)
$$

As the air flow approaches the saturation point, it takes more time to vaporize the left water parcels. Therefore, reaching the saturation temperature in the entrance without hyper-sprinkling is not operative, which in this regard choosing the limited design of two degrees has been designed in order to minimize the mentioned hyper-sprinkling. Calculated flow amount based on wet and dry environment temperature $\left(T_{d b}, T_{w b}\right)$, as the main control variables in the controlling planning aren't applied because the accumulated water in the depleted part via gas turbine never vaporized, so no cooling action happens. In this result, current span of the secondary pre-assumption of environmental conditions $\left(T_{d b}, T_{w b}\right)$ will be calculated which set up as a safe area for water injection. The inlet filter geometry and nozzle array on monotonous distribution of injection fog and helping depletion of water is effective [5].

With increase of injection Debbie, the temperature of hotter area goes down, until be approached the saturation point and afterwards water vaporizes in a very small amount and lots of it will be depleted.

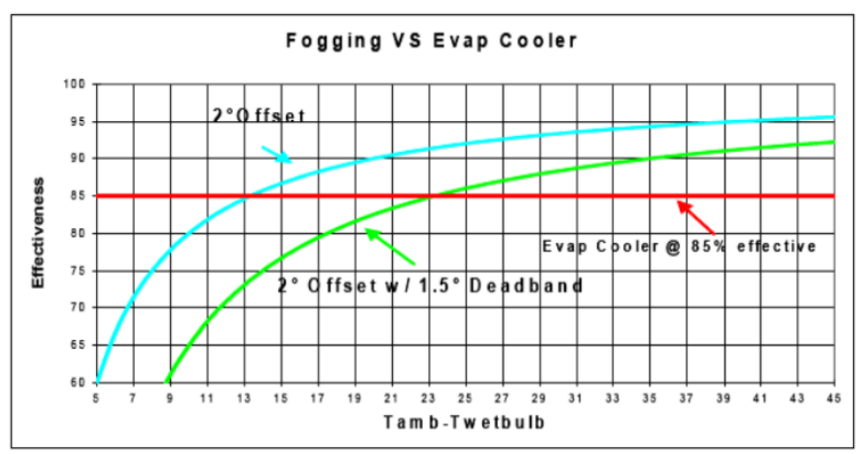

Fig. 5. Fog-pumping system effectiveness.

The amount of output power increase significantly depends on environmental conditions. The low cooling ability $\left(T_{d b}, T_{w b}\right)$ causes to decrease the cooling effectiveness. For example, if two degrees segregation of saturation as the control point has been planned, it would be possible to gain the $80 \%$ output in the best conditions by fog-pumping. If the fog-pumping is performed with 30 degrees of cooling ability. The output will be about $93 \%$.

\section{B. Applications}

Fog-pumping systems in comparison with the bed-based vaporizing coolers have the same applications. The greatest advantage and effectiveness of the coolers appears when the weather conditions are hot and dry. The assuring variables such as water quality, cost, pollution and exploiting from power planet can limit the fog-pumps use.

\section{Economic Features}

Fog-pumping systems according to installation and exploitation comparing with the bed-based vaporizing coolers are a little costly. Generally installation costs add up 40-70 dollars to the real value of the production capability per KW. Exploitation cost are less, the needed peripheral equipment in such systems are of the bed-based vaporizing coolers though.

\section{The Other Advantages, Risks and Considerations}

According to mentioned to approach the dry temperature of the environment nearer to saturation point in a high 
relative humidity, for the bed-based coolers, is operable, although in most cases. Fog-pumping systems provide a flexible approximate entering that many vaporizing coolers come along according to the environment. Another advantage of the phase control pump is actually its flexibility or conformity with an open control. Water transferring causes worry and would be able to minimize the phase pumping and its conformity with environment. The hyper-sprinkling causes compressor's blade erosion. The fog-sprinkling pump is compressed that needs to a minimum service and is easily located in the general array or arrangement of the power planet. Fog-sprinkling systems feed mineral water and then they needed the inlet channel components model of rustproof steel. Besides, the material of distribution pipes should be made of rustproof steel.

\section{MEChanicAl CHILLING SYSTEMS AND THERMAL ENERGY STORAGE}

\section{A. General Features}

Mechanical chilling is used for cooling systems to transmitting the needed to heat to stabilize the inlet air temperature, which is independent from the conditions of site's location to gas turbine. The systems that more are as following:

1) Radial package chillers (Fig. $6 \& 7$ ).

2) Package chillers with deflexive compressors (Fig. $6 \&$ 7)

3) Absorbent chillers (Fig. 8).

Radial package chillers are units that are cooled with water. They operate in the performance span of 1500-4500 tons. These units are classifiable in order to meet the necessary chill for inlet air flow in the gas turbine via the cooling coils. The load or the charge of inlet cooling coil for the $185 \mathrm{MW}$ gas turbine with the conditions of environmental air of dry temperature and of wet temperature and dry temperature of the outlet air flow of is approximately 5700 tons. The cooling chillers with air lean to be located in the family of the centrifugal compressors. For example, the chilling capacities' span ranges from 1200 to 3600 tons. Centrifugal compressors package units can be mixed together in order to reach whatever amount of the inlet air coil load the absorbent chillers which specifically are cooled by water, placing in the span of 800 to 200 tons. The inlet air temperature of the turbine mainly ranges 45 to 55 and these temperature are for the air that the cooling coil comes out. This limitation is because of the saturated air which comes out of the cooling coil and there is the possibility of shaping ice in the gas turbine compressor and, finally, happening pressure fall down. All above chilling systems are able to provide the inlet air between 45 to $55 \mathrm{~F}$. The radial and centrifugal package systems work electricity. While the absorbent chillers require a thermal source for its generator which this amount of heat might be provided from gas, vapor, hot water or gas turbine output. The main source of this chiller to make heat is vapor, which is used in the combined cycle power planet [6]. The related loads of the subsidiary equipment such as pumps and fans from the internal consumption loads. For example, the radial package chilling system, which is cooled by water has the internal consumption load of 8.6 MW that is used for a
$185 \mathrm{MW}$ turbine in the dry environmental conditions of 105 , wet and also the inlet temperature of compressor.

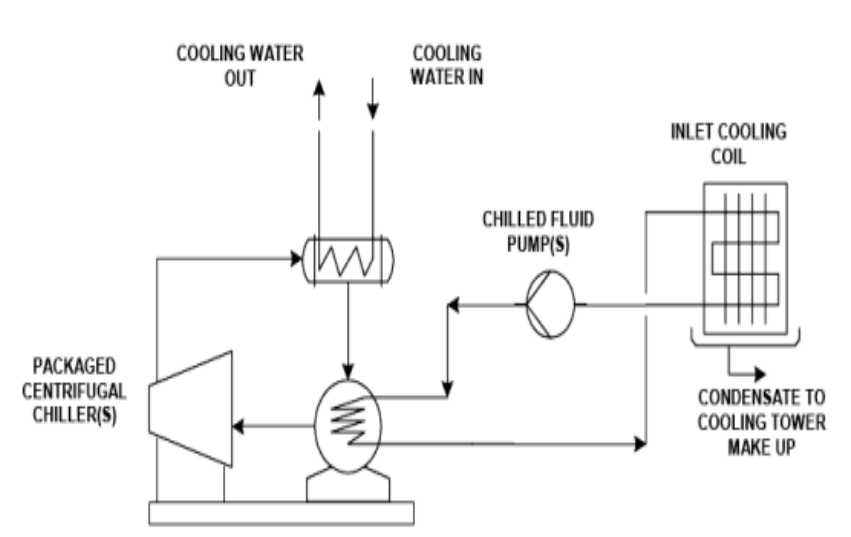

Fig. 6. The schema of a mechanical chilling system to be used for cooling the inlet air of turbine.

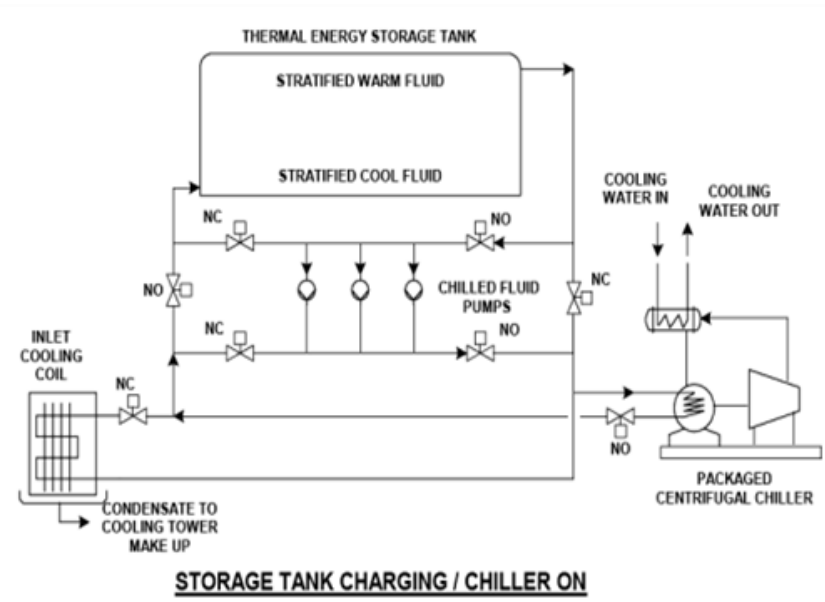

Fig. 7. The schema of mechanical chilling system as a kind of thermal energy storage system to be used for cooling the inlet air of turbine.

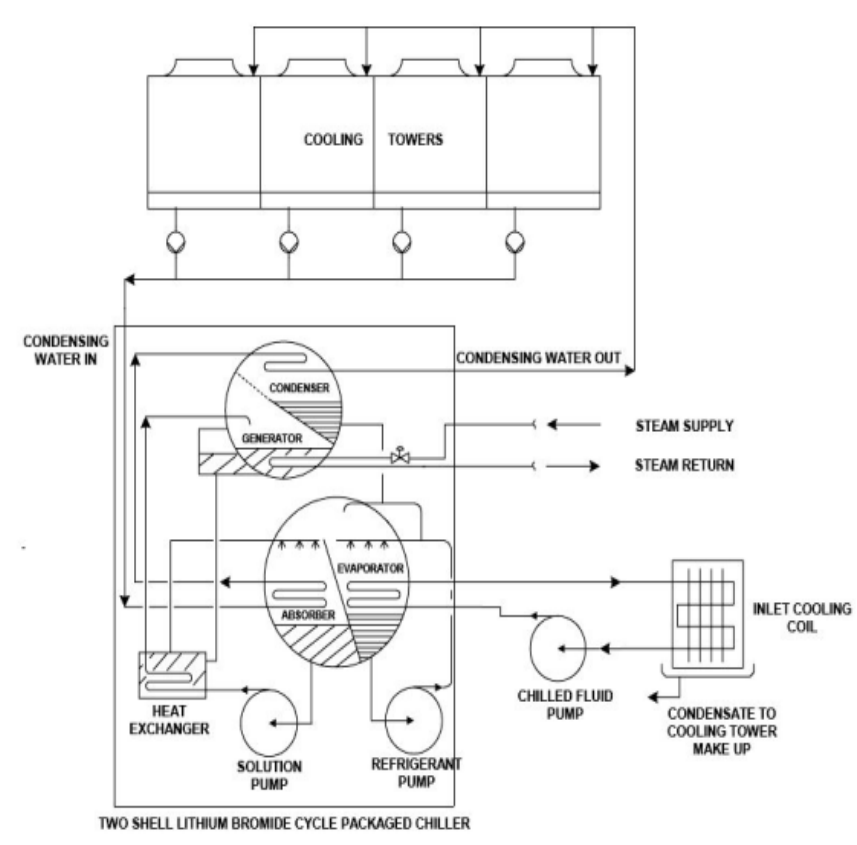

Fig. 8. The schema of absorber chiller used for cooling the unlet air of the turbine.

\section{B. Applications}

In both conditions of continual and courier power planet work, the mechanical chilling works which economically 
supplying inlet air temperature to the compressor in a fixed amount is justifiable [7]. Units with the same as courier performance conditions, have more utility in comparison with the use of the thermal energy storage systems along periods of requirement out of power planet courier.

According to mentioned, the thermal energy storage systems work with the same chilling equipment and subsidiary components but, they need a stored tank of extra cold fluid and pump. The thermal energy storage systems along periods of requirements out of the courier of power planet in the main orbit of the chiller are set and loaded in this period of time. Along time periods of the requirement of peak load of mechanical chilling equipment inactivated and the cold fluid will be circulated by the pump [8].

\section{Economic Feature}

Mechanical package chiller systems have the highest investing and exploitation costs in all the introduced systems in this paper. With the use of mechanical chilling systems, the mount of the internal consumption load will be increased. (For example the compressor of the chiller, the pumps of the circulation of the cold fluid and condenser, the fans of the subsidiary cooling tower) radial and sweeping chillers with their helping equipment in comparison with absorbent chillers need more the internal consumption power: of course, if there is the necessary thermal energy. The conditions will be better, whether or not. The absorbent chillers systems are costlier than the direct chillers.

\section{Other Advantages, Risks and Considerations}

All three mentioned chiller systems are able to gain the acceptable inlet air conditions than environmental conditions. Absorbent chillers can decrease their internal consumption by using thermal loss. These systems could be manufactured and assembled in the covered site with the aim of decreasing installation operation. The need components with the package of chiller includes cooling coils of the inlet air, pumping for necessary joint, heat insulator, condense pumps. To provide an outlet and vapor power planet is easily possible based on cooling water power planet structure, if necessary. Although such systems were packaged in order to reduce their dimensions, but by applying two turbines of $185 \mathrm{MW}$. The needed surface will be 5400 square feet approx. if the package chiller systems are used, the expansion of this system should be under consideration.

TABLE I: COMPARATIVE MATRIX OF THE STUDYING SySTEMS

\begin{tabular}{|c|c|c|c|c|c|}
\hline $\begin{array}{l}\text { System } \\
\text { Type }\end{array}$ & $\begin{array}{c}\text { Media Based } \\
\text { Evaporating Cooling }\end{array}$ & Fogging & $\begin{array}{l}\text { Mechanical Chilling. } \\
\text { Water Cooled }\end{array}$ & $\begin{array}{l}\text { Mechanical Chilling. } \\
\text { Air Cooled }\end{array}$ & $\begin{array}{l}\text { Absorption Chilling. } \\
\text { Water Cooled }\end{array}$ \\
\hline $\begin{array}{c}\text { System } \\
\text { Description }\end{array}$ & $\begin{array}{l}\text { Evaporative cooling is } \\
\text { provided through use of a } \\
\text { fluted cellulose base } \\
\text { media pads. the pads are } \\
\text { located within the filter } \\
\text { house airstream and } \\
\text { wetted from an } \\
\text { acceptable site source. } \\
\text { heat from the airstream is } \\
\text { given up to the water in } \\
\text { the evaporative media }\end{array}$ & $\begin{array}{l}\text { Inlet airstream is } \\
\text { cooled through the } \\
\text { direct infusion and } \\
\text { evaporation of minute } \\
\text { water particles into the } \\
\text { airstream. heat from the } \\
\text { airstream is given up to } \\
\text { the water droplets } \\
\text { evaporation thereby } \\
\text { reducing inlet air } \\
\text { temperature. }\end{array}$ & $\begin{array}{l}\text { inlet airstream } \\
\text { cooling is accomplished } \\
\text { through the use of an } \\
\text { electric packaged chiller } \\
\text { system ( water cooled, } \\
\text { cooling water source or } \\
\text { water) in conjunction } \\
\text { with inlet air heat } \\
\text { exchange coil ( chilled } \\
\text { water or Glycol ) }\end{array}$ & $\begin{array}{l}\text { inlet airstream } \\
\text { cooling is accomplished } \\
\text { through the use of an } \\
\text { electric packaged chiller } \\
\text { system ( air cooled, } \\
\text { typically fin type } \\
\text { coolers ) in conjunction } \\
\text { with inlet air heat } \\
\text { exchange coil ( chilled } \\
\text { water or Glycol ) }\end{array}$ & $\begin{array}{l}\text { inlet airstream cooling } \\
\text { is accomplished through } \\
\text { the use of a } \\
\text { lithium-bromide } \\
\text { absorption chiller system } \\
\text { ( water cooled, cooling } \\
\text { tower ) in conjunction with } \\
\text { inlet air heat exchange coil } \\
\text { ( chilled water or Glycol ) }\end{array}$ \\
\hline $\begin{array}{c}\text { Installed } \\
\text { Cost }(\$ / \mathrm{KW} \\
\text { added }) \\
\end{array}$ & $25-50$ & $45-70$ & $200-500$ & $250-550$ & $300-700$ \\
\hline $\begin{array}{r}\text { Operating } \\
\text { / Maint Cost }\end{array}$ & Low & Low & High & High & High \\
\hline $\begin{array}{l}\text { Heat Rate } \\
\text { Change }\end{array}$ & -1.5 to $-3 \%$ & -1.5 to $-2.5 \%$ & -1 to $-2 \%$ & -1 to $-2 \%$ & -1 to $-2 \% *$ \\
\hline & & & & \multicolumn{2}{|c|}{ *If exhaust gas wasted heat can be applied } \\
\hline $\begin{array}{c}\text { Power } \\
\text { Output } \\
\text { increase } \\
\text { (Varies W/ } \\
\text { Ambient) }\end{array}$ & 5 to $10 \%$ & 5 to $10 \%$ & Up to $15 \%$ & Up to $15 \%$ & Up to $20 \%$ \\
\hline
\end{tabular}

\section{CONCLUSION}

Combustion turbine capacity:

Is a function of mass Debbie of the passing current of the compressor that generally is controlled by the change of the inlet air temperature. The kind of the cooling system, which were reviewed in this paper are as below; the vaporizing coolers (wet based and fog-pumping systems) and the mechanical chilling (by using electrical power and absorbent system) being with or without the storage system of the thermal energy-that is suitable to present by power planet owners with the aim of increasing the pure strength of the gas turbine output. You can find same adv. Of these systems in the following;

The wet-based vaporizing cooling system-the low risk, exploit ability in a short time, usability in potable water with the least electrical controls.

Vaporizing cooling system with using fog-pumping systems-having a permanent process for reaching the humid temperature, having well-set and compact pumping equipment, suitable for the load control in rather conditions; creation the least pressure downfall for the more existing turbine systems without any changes in the inlet channels or any changes in dimensions of the filter house. 
The refrigerant chillers-nearly sure about gaining the least temperature of the inlet air, efficient for continually exploitation or in the peak conditions and also installation ability with the shape of package.

The absorbent chilling-nearly sure about gaining the minimum temperature of the inlet air, efficient for continually exploitation or in the peak condition and also installation ability with the shape of a package. While the cooling systems have proved their pertinence, every site might have the best choice for their economical aspect basis. This choice must be done based on the precise study of ASHARE data, meteorological data, accurate study of the potable water resources and also the survey of finance taxes, credits, etc.

The main key of each choice to decide about the investment depends on its economical adv. This matter easily and with the use of economical analysis will be determined based on life time costs. Of course the increase of studying variables causes having more analyses to be sure about your choice. This matter consist a preliminary analysis which contains things such as the investment cost, the load amount in the different environmental conditions, the future value of the energy, exploitation cost, taxes, investment and insurance (see Table I).

The final result is that the age cost. Investment revocability amount, are the main factor to choose the best economical-performance option.

\section{REFERENCES}

[1] D. W. Shepherd, "Application of fogging and wet compression with a feed back control system," presented at Power-GEN International, Orlando, Florida, December 2006.
[2] E. T. Guimaraes, "A new approach to turbine inlet cooling," ASHRAE Transactions, vol. 107, p. 1, 2001.

[3] D. E. Willems and P. D. Ritland, "A pragmatic approach to evaluation of inlet fogging system effectiveness," presented at the International Joint Power Generation Conference, Atlanta, Georgia, June 16-19, 2003.

[4] J. S. Andrepont, "Maximizing power augmentation while lowering capital cost per mw via turbine inlet cooling (TIC) with thermal storage (TES)," Proceeding of Electric Power, Atlanta, Georgia, May 2006.

[5] J. E. Kraft, Turbine Inlet Cooling System Comparisons, Energy-Tech, pp. 36-37, August 2006.

[6] Method of Testing Direct Evaporative Air Coolers, ANSI/ASHREA Standards 133-2001.

[7] ASHREA, 2000 HVAC Systems and Equipment Handbook, Atlanta, Georgia

[8] J. Langreck, "Cogen-absorption paints for refrigeration purposes and turbine air inlet cooling," Cogen Onsite Power Production, pp. 46-49, March-April 2000.

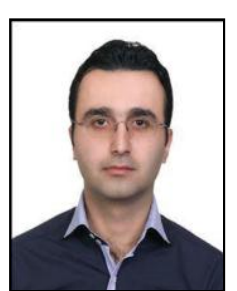

Seyed Ali Sakhaei is a master of science in mechanical engineering (energy conversion). He was born in Amol, Iran. He has been working as a rotary eq. expert in National Iranian Oil Company (M. S. P. KALA NAFT Co.) since 2007 in Tehran, Iran. He has also been working as a lecturer in Eyvanekey University since 2011 in Semnan, Iran. His research interests include rotary equipment and fluid mechanic.

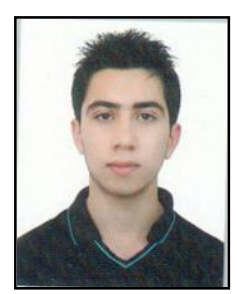

Mahbod Safari was born in Tehran, Iran. He is a B.S candidate in mechanical engineering at Islamic Azad University Tehran East Branch. His research interests include rotary equipment and fluid dynamic and manufacturing. 